\title{
Effects of hook shape and cement replacement materials on pullout behaviour of steel fibres
}

\author{
[ Elyas Malaki Zanjani, Stephanie Barnett, David Begg ]
}

\begin{abstract}
The purpose of this study is to investigate the effect of hook shape and material of high tensile strength hooked end steel fibres and the impact of cement replacement materials on pullout behaviour of steel fibres from cementitious composites. The cement replacements which have been used in this research included silica fume, pulverised fuel ash, limestone filler and ground granulated blast-furnace slag. In total, more than 800 samples have been manufactured for experimental research on compressive strength and pullout behaviour of hooked end steel fibres from cementitious matrices. The effects of parameters such as water/binder ratio, cement replacement content, age of sample, hooked end shape and tensile strength of fibre on fibre-matrix pullout behaviour were determined. The results of tests and analysis indicate that hook shape, tensile strength of fibre and silica fume affect the maximum pullout force and ground granulated blast-furnace slag can significantly improve the residual pullout energy which would be useful for the optimisation of steel fibre reinforced concrete. The outcome of this research may be useful to widen the potential applications of the material across civil engineering. (Abstract)
\end{abstract}

Keywords-Steel Fibre, Pullout, Cement Replacement, Cementitious Materials

\section{Introduction}

Concrete is strong in compression but because of its low tensile strength, one of the main improvements which it needs to have is reinforcement against tension. Steel has been the most common reinforcement material for centuries. However, steel in shape of fibre has been introduced to the industry for less than 150 years. Using this type of reinforcement is now becoming more popular as the need for quick construction and low cost production is more noticeable. Particularly for precast elements, manufacturing reinforcement cages and storing them for a long period of time is costly. New types of fibres are still being developed by manufacturers while the design codes for use of steel fibre reinforced concrete (SFRC) are also still in development. These can assist the engineers to use this material as sole or hybrid reinforcement solution in different civil engineering applications.

Fibre-mortar bonding is one of the most important factors in SFRC and is even more so in these new types of steel fibres where ductility is provided by the fibres stretching as well as pulling out of the matrix. In this research project, effect of different properties of fibres on their pullout behaviour are studied experimentally.

Today, concrete is the most widely used man-made material. It mainly consists of a mixture of aggregate

Elyas Malaki Zanjani, Stephanie Barnett, David Begg

University of Portsmouth

United Kingdom particles and binding agents possibly with other admixtures and additives and is being used in several applications.

However, production of the main ingredient of concrete, cement, is highly energy and emissions intensive. Therefore, reducing a small percentage of this emission can make a huge improvement to environment and so there is potential for such material development to help reduce the carbon footprint associated with concrete. Replacing cement by other cementitious materials could be an effective idea. The effect of different cement replacement materials (CRM) on mechanical properties of SFRC and their impact on fibremortar binding are studied in this project.

\section{Literature review}

Natural materials in the shape of fibre as reinforcement were used in air-dried loam bricks through the addition of straw fibres or animal hair thousands of years ago [1]. Today, for practical purposes and mechanical modelling, fibre reinforced concrete (FRC) that is generally defined as composites with two main components, the fibre as discontinuous reinforcement and the cementitious matrix, are being used in variety of applications [2]. Different natural fibres, glass fibre, synthetic fibres and steel fibre are the most common reinforcement materials used in FRC.

In SFRC, fibre is assumed to be randomly oriented and distributed within the volume of the composite and to work together with matrix, through bond, and provide a three dimensional reinforcement system to make an effective composite. The matrix, whether it is a paste, mortar, or concrete is assumed to contain all the aggregate particles, additives specified and entrapped air voids [2].

As a result of many experimental studies on investigating the properties of SFRC, below is the list of SFRC advantages [2,4,5].

- Strength improvement (blast strength, flexural strength and permanent strength) and less maintenance requirement

- Economic compared to some other materials and able to be cast in any shape

- Excellent resistant to water, high temperature and fire and less major corrosion

- Increase the deformation, disintegration, ductility, toughness, energy absorption capacity

- $\quad$ Resistance to fatigue, flaking, shrinkage cracking and concentrated loads

The flexural behaviour of plain and fibre reinforced concrete are quite different. Plain concrete will fail immediately after exceeding the crack strength amount. There is no residual strength after the peak load for plain concrete. However, in SFRC, after exceeding the first peak load, the micro-cracks are opened and the fibres start to act. 
Therefore, SFRC is capable of bearing loads even after reaching the crack strength and with cracked tensile zone. The fibre bridging force comes from the transfer of stress at the fibre-matrix interface, which is achieved by the bond defined as the shear stress acting on the interface and results in the post-cracking strength of steel fibre reinforced concrete $[6,7]$.

The properties of SFRC are affected by the properties of both the fibres and the matrix. In addition to the material of fibre, the formation of end anchorage of steel fibres is also important in terms of pullout force (and hence post-peak load carrying capacity). The capacity of the fibre-matrix bond depends on the nature of the geometrical properties of the fibres and the strength of the surrounding matrix $[1,8]$. Hooked ends are one of the most effective features that can improve the resistance of fibres to pullout and improve the bonding strength of the matrix. Different studies show that hooked end steel fibres are more effective in SFRC [3,9].

The factors that affect compressive strength of concrete will also affect its flexural performance, especially its flexural strength. In addition, the microstructure of the matrix in close proximity to the fibre will affect the strength of the bond between the two and therefore the flexural toughness of SFRC. Generally, reduction of water/cement (w/c) ratio improves most of the desirable properties of the hardened concrete such as compressive, tensile, flexural, bond and shear strengths, water tightness and resistance to abrasion and weathering and reduces water absorption and shrinkage of the mortars [10,11]. From the results of experimental studies on SFRC, it can be concluded that changing the w/c ratio has the same effect on compressive strength as it has on plain concrete. However, it can affect the flexural strength of SFRC more. There is some evidence to suggest that different steel fibres have different behaviour considering $\mathrm{w} / \mathrm{c}$ ratio and so optimising the w/c ratio for designing a particular SFRC mix is critical [12].

In order to study the effect of different cementitious materials on SFRC, four different CRM, silica fume, pulverised fuel ash (PFA), limestone filler and ground granulated blast-furnace slag (GGBS), were chosen for this project regarding to their behaviour in concrete and practicality in the industry. Silica fume is a type of Supplementary Cementing Material (SCM) which is a byproduct of the silicon metal and ferrosilicon alloys manufacturing and it is prepared by burning $\mathrm{SiCl}_{4}$ in an oxygen rich hydrocarbon flame [13]. Silica fume improves early compressive strength, flexural strength, toughness, modulus of elasticity, durability and resistivity to chemical attack, abrasion and decreases the permeability [14,15]. Moreover, it is reported in different studies [16,17,18] that $5-15 \%$ of silica fume can improve the workability of concrete and it declines by increasing the dosage and increases flexural strength of SFRC. Due to extremely fine particles, silica fume plays an important role in filling the transition zone between aggregates, paste and fibres which can effectively enhance the fibre-matrix interfacial properties, especially in fibre pullout energy [19].

PFA is a by-product of thermal power generating stations and is associated with improvements in durability, resistance to sulphate attack and a reduction in the effects of the alkali-aggregate reactions [20]. By replacing 30 per cent of the total cement content with PFA, the overall environmental impact is shown to be reduced by at least 17 percent for the same 28 day strength [21]. PFA contains high volumes of $\mathrm{SiO} 2$ and $\mathrm{Al} 2 \mathrm{O} 3$ and iron oxide (Fe2O3) totally around $70 \%$ by mass and particles range in size from $0.5 \mu \mathrm{m}$ to $300 \mu \mathrm{m}[22,23]$. The results show by increasing the PFA content, slump increases and after a certain level, the compressive strength decreases [24].

Although limestone is chemically inert, but limestone fines can contribute towards strength by a physical, voidfilling mechanism due to their fine particle size. Fillers, generally, are particles which can be added to material to reduce the consumption of other basic binders for specific requirements of mixture, environmental issues or financial solutions [25]. Researches on limestone filler concrete illustrates that the filler improves the workability, mechanical behaviour (compressive and flexural strength) [26, 27, 28] and water-tightness [29] with an optimum volume of $5-10 \%$.

As regards ground granulated blast-furnace slag, this is a by-product of the iron-making process and because of its high calcium silicate content, it has excellent cementitious content [30]. It is a latent hydraulic binder which when is mixed with water, it slowly sets and hardens [31]. In short terms, the compressive strength decreases by increasing the slag content and the effect is more evident at early ages [32]. A few studies are carried out on the effect of GGBS in SFRC. The results of a research show that the reduction of compressive strength due to addition of steel fibres in SFRC is higher in normal concrete compared to concrete containing GGBS and splitting tensile strength enhancement is higher in GGBS concrete reinforced with steel fibres [33].

\section{Methodology}

A detailed investigation of the effects of varying water/binder ratio and type and level of CRM on the properties of SFRC, specifically the fibre-matrix bond, was carried out.

\section{A. Materials}

The properties of steel fibres been used in this research are presented in Tables 1. The cement used was high strength Portland cement (CEM1 52.5N). Silica fume, PFA, limestone filler and GGBS as other cementitious materials are used and discussed previously. Aggregates were all natural flint aggregate and were oven dried before use. The maximum aggregate size was $10 \mathrm{~mm}$.

TABle 1 SteEl Fibre Properties [34]

\begin{tabular}{|c|c|c|c|c|c|}
\hline Fibre Series & & TYPE I & TYPE II & TYPE III & TYPE IV \\
\hline \multirow{2}{*}{$\begin{array}{c}\text { Material } \\
\text { properties }\end{array}$} & $\begin{array}{l}\text { Tensile } \\
\text { Strength }\end{array}$ & $1160 \mathrm{MPa}$ & $2300 \mathrm{MPa}$ & $1500 \mathrm{MPa}$ & $2300 \mathrm{MPa}$ \\
\hline & $\begin{array}{l}\text { Young's } \\
\text { Modulus }\end{array}$ & $\begin{array}{c} \pm 210000 \\
\mathrm{MPa}\end{array}$ & $\begin{array}{c} \pm 210000 \\
\mathrm{MPa}\end{array}$ & $\begin{array}{c} \pm 210000 \\
\mathrm{MPa}\end{array}$ & $\begin{array}{c} \pm 210000 \\
\mathrm{MPa}\end{array}$ \\
\hline \multirow{3}{*}{ Geometry } & $\begin{array}{l}\text { Hook } \\
\text { Shape }\end{array}$ & & & & \\
\hline & Length & $60 \mathrm{~mm}$ & $60 \mathrm{~mm}$ & $60 \mathrm{~mm}$ & $60 \mathrm{~mm}$ \\
\hline & Diameter & $0.90 \mathrm{~mm}$ & $0.90 \mathrm{~mm}$ & $0.90 \mathrm{~mm}$ & $0.90 \mathrm{~mm}$ \\
\hline $\begin{array}{c}\text { Fibre } \\
\text { network }\end{array}$ & & $\begin{array}{c}3183 \\
\text { Fibres/kg }\end{array}$ & $\begin{array}{c}3183 \\
\text { Fibres/kg }\end{array}$ & $\begin{array}{c}3183 \\
\text { Fibres/kg }\end{array}$ & $\begin{array}{c}3183 \\
\text { Fibres/kg }\end{array}$ \\
\hline
\end{tabular}


Proc. Of the International Conference on Advances in Civil, Structural and Construction Engineering - CSCE 2016 Copyright ( $($ Institute of Research Engineers and Doctors. All rights reserved. ISBN: 978-1-63248-101-6 doi: 10.15224/ 978-1-63248-101-6-11

\section{B. Mix designs}

Mix proportioning was based on reference to literature, previous work by the author and trial mixes to determine water/binder ratios, types and percentage levels of CRM $[31,35,36]$ for the study. Aggregate content was kept constant throughout for concrete mixes. However, aggregates were removed from some of the mixes in order to study the effect of CRMs and fibre type on fibre matrix bonding in cementitious pastes. In order to add steel fibres and avoid losing workability, the slump of concrete was kept in the range of $100 \mathrm{~mm}-200 \mathrm{~mm}$ by varying superplasticizer (liquid polycarboxylate water reducer) content, so this varies depending on both w/b ratio and CRM type and level. The mixes are named based on their water/binder ratio, the type of CRM used and the replacement percentage. Therefore, 25,35 and 45 refer to w/c ratios of $0.25,0.35$ and 0.45 respectively. CEM, SF, PFA, LF and GS refer to the cementitious material used. For example, C25SF10 refers to 0.25 water/binder and $10 \%$ replacement of cement by silica fume. CEM stand for cement and is the control mix.

Totally, 282 cubes were manufactured for compressive strength testing and 396 cubes for the pullout testing. The samples for compression testing were cast in $100 \mathrm{~mm}$ polystyrene moulds for concrete samples and in $50 \mathrm{~mm}$ steel moulds for paste samples. The pullout test samples were also casted in $50 \mathrm{~mm}$ cube steel moulds. A sole steel fibre was embedded manually into the cubes after pouring. The embedded length of the fibre was kept constant at $30 \mathrm{~mm} \pm$ 5 and perpendicularly to the upper face. The concrete was compacted by using a vibrating table from almost the middle of pouring to final adjustment of the fibres in their positions to remove likely voids particularly around the fibre. The samples were demoulded 24 hours later. They were cured in water tanks at normal laboratory temperature $\left(20{ }^{\circ} \mathrm{C}\right)$ till their test ages. The samples were tested at the ages of 7, 28 and 56 days.

\section{Testing procedure}

The density of the $100 \mathrm{~mm}$ cubes was measured in accordance to [37]. The results of these tests are not presented here but generally showed that increasing CRM levels decreased the density.

Compressive strength of the cubes was measured according to [38] with a loading rate of $3 \mathrm{KN} / \mathrm{s}$. Depending on mix and age of the sample, different failure patterns were seen from slight cracks to explosive failures.

For the pullout test, the sample was placed in a predesigned steel plate. The fibre protrudes through a hole in the middle of the plate and was held with the grips of a Zwick/Roell universal testing machine (Fig. 1). The test was conducted under a controlled crosshead speed of $3 \mathrm{~mm} / \mathrm{min}$ and continued until the measured load had decreased by $99 \%$ of the maximum load recorded.

\section{Results}

\section{A. Compressive strength}

The compression test results of concrete samples reveal that Higher w/b ratio gives lower compressive strength in concrete mixes either containing CRM or not. In addition,

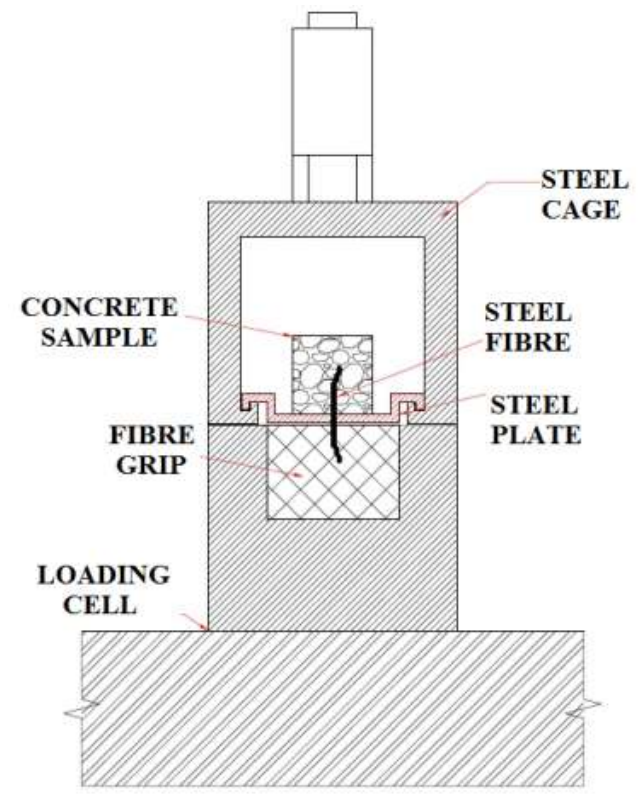

Figure 1. Pullout test arrangement

the effect of CRM on compressive strength is higher in concrete with lower w/b ratio. Apart from silica fume, other materials decrease the compressive strength in 0.35 and 0.45 $\mathrm{w} / \mathrm{b}$ ratios (Fig. 2). Although, in some mixes the compressive strength is almost same as the CEM concrete, which means replacing the cement with cheaper and greener materials is still an effective solution.

However, the results of compression tests of paste mixes show that replacing cement with different CRMs improve this property. Replacing cement by silica fume (10\%), PFA $(20 \%)$, limestone filler $(10 \%)$ and GGBS $(50 \%)$ increased the compressive strength by $20 \%, 40 \%, 48 \%$ and $17 \%$, respectively (Fig. 3).

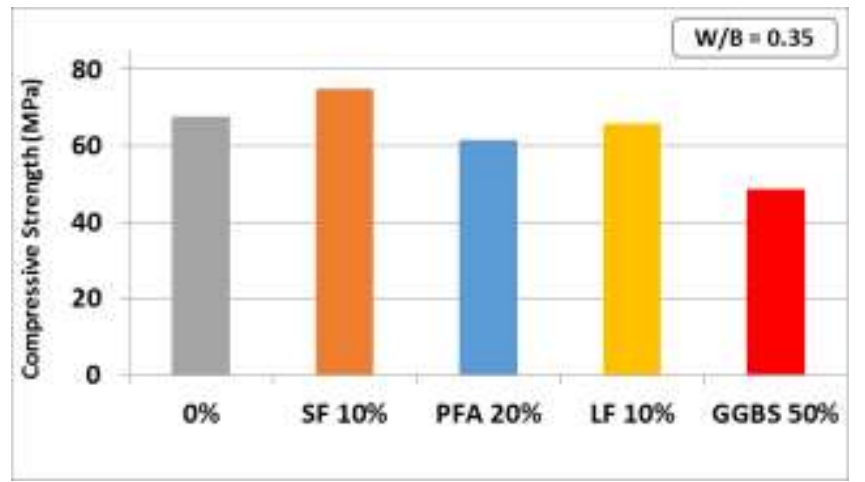

Figure 2. Effect of CRM on compressive strength in concrete samples

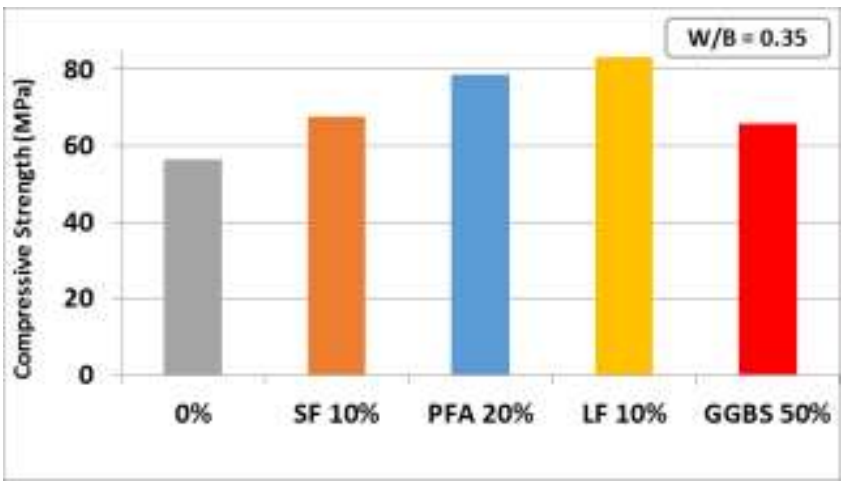

Figure 3. Effect of CRM on compressive strength in paste samples 
Proc. Of the International Conference on Advances in Civil, Structural and Construction Engineering - CSCE 2016 Copyright @ Institute of Research Engineers and Doctors. All rights reserved.

ISBN: 978-1-63248-101-6 doi: 10.15224/ 978-1-63248-101-6-11

\section{B. Pullout strength}

Fig. 4 illustrates a typical behaviour for the type IV steel fibre plotted based on the result of pullout tests. After the peak load, which usually happens at a displacement around $3 \mathrm{~mm}$, the load starts to decrease dramatically with increasing displacement. However, the hooks of the fibre appear to cause some steps in the downward section of the curve. These steps represent the effect of the hooks' shape on the pullout force. When the hooks get into the tension condition, they became almost straight and are pulled out by carrying on the test. At around $14 \mathrm{~mm}$, the fibre is almost straight in its own tunnel inside the sample and eventually comes out of the sample. In some cases, the fibre was not able to bear the straightening force and snapped at the peak load. Therefore, the pullout process can be divided into three stages: linear-elastic deformation stage, partial debonding stage, and full debonding followed by a frictional pull-out stage $[33,39]$.

There are large variations in results from replicate samples. The authors believe that this is due to the manual placing of the fibres in the compacted concrete samples, so even an individual aggregate particle close to the fibre or variation of fibres embedded length could affect the pullout strength considerably. The results of a few individual samples were therefore ignored for calculating the average strength of the mix. According to the results, there is no obvious improvement in pullout max force by using the CRM. However, similar to compressive strength, there is slight reduction in the pullout strength of the fibres by increasing the $\mathrm{w} / \mathrm{b}$ ratio. In addition, the pullout strength is increasing dramatically up to 28 days and slightly changes after then.

To avoid the above issue with aggregate particles and to evaluate the pullout behaviour and bonding properties of fibres, more samples were manufactured. Similarly, a single fibre was embedded in samples but containing cementitious paste without any fine or coarse aggregate. The result of these test where more reliable.

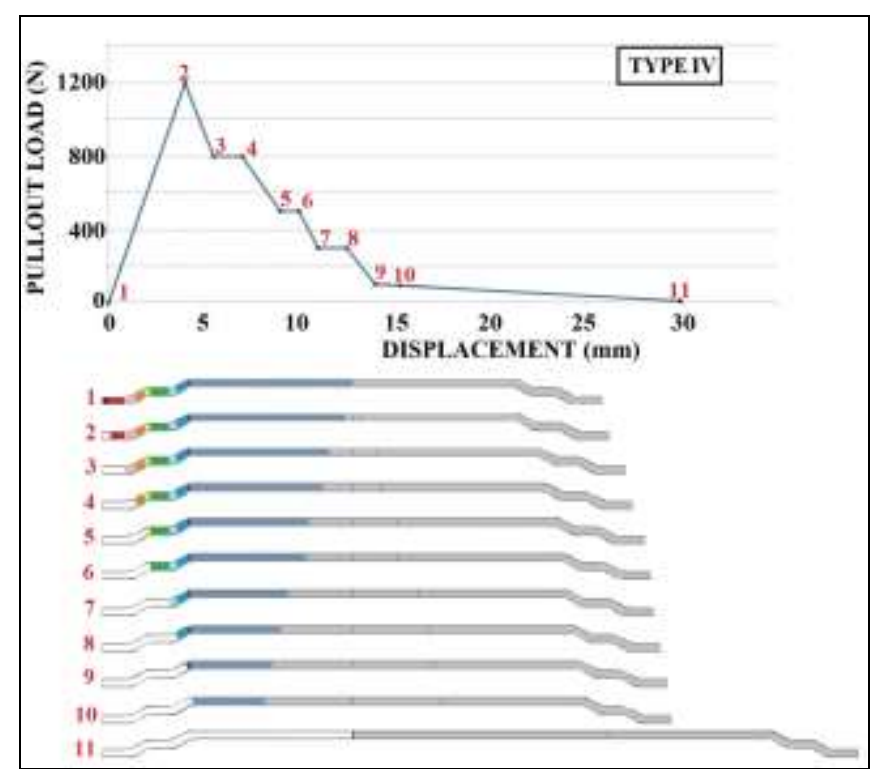

Figure 4. Pullout procedure

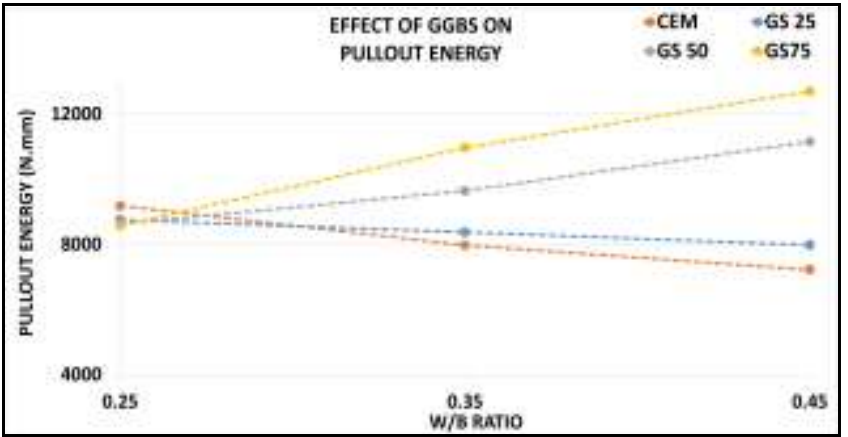

Figure 5. Pullout energy of type IV fibre embedded in GGBS concrete

Fig. 5 shows the pullout energy of type IV fibres embedded in samples containing GGBS at 28 days age. One of the most interesting results is the enhancement of the pullout energy of these mixes by increasing the w/b ratio. This is more obvious at the age of 28 days than at the earlier test age of 7 days. The pullout force drops significantly after the hooks are straightened at displacement around $12-14 \mathrm{~mm}$. However, some mixes containing GGBS have higher pullout force at higher displacements, even up to $30 \mathrm{~mm}$. This residual strength of the fibre-matrix bond in the frictional pullout stage makes the difference in pullout energy (Fig. 3). However, high displacements would not happen in service conditions for which the crack opening of $0.3 \mathrm{~mm}$ or smaller are generally expected and acceptable.

Fig. 6 compares the results of the four types of fibres, in terms of maximum pullout load. As mentioned before, these fibres have different hook shapes and also the materials used for manufacturing these fibres are different. However, length and diameter of fibres are the same. It is interesting that improving hooks and material in type IV fibres increased the pullout strength and pullout energy more than $120 \%$ compared to type I, $90 \%$ compared to type II and $20 \%$ compared to type III. Silica fume also increased pullout strength for all the fibre types in these mixes

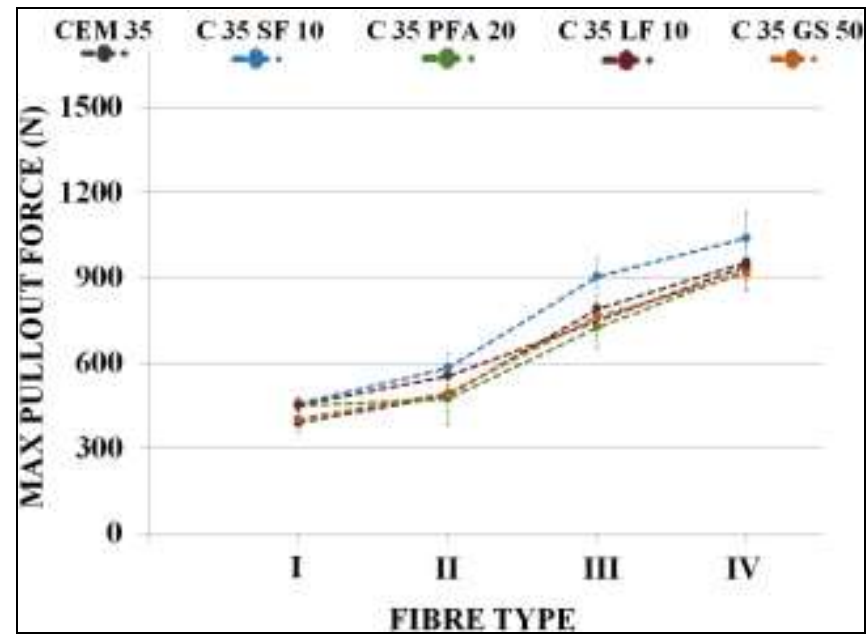

Figure 6. Effects of steel fibre type and CRM on pullout strength in paste samples

\section{Acknowledgment}

Special thanks to technicians of concrete and structure laboratories of the University of Portsmouth. The authors acknowledge Bekaert (UK) for their material support. 


\section{References}

[1] Maidl, B. R. (1995). Steel fibre reinforced concrete. Berlin: Ernst \& Sohn.

[2] Mo, Y. L., \& Shi, C. (Eds.). (2008). High-performance Construction Materials: Science and Applications. World scientific.

[3] Soutsos, M., Le, T., \& Lampropoulos, A. (2012). Flexural performance of fibre reinforced concrete made with steel and synthetic fibres. Construction and Building Materials 36, 704-710.

[4] Barros, J. A., Taheri, M., Salehian, H., \& Mendes, P. J. (2012). A design model for fibre reinforced concrete beams pre-stressed with. Composite Structure 94, 2494-2512.

[5] Ibrahim, I., \& Che Bakar, M. (2011). Effects of mechanical properties of industrial steel fibres addition to normal weight concrete. Procedia engineering 14, 2616-2626.

[6] Soetens, T., Van Gysel, A., Matthys, S., \& Taerwe, L. (2013). A semi-analytical model to predict the pull-out behaviour of inclined hooked-end steel fibres. Construction and Building Materials, 43, 253-265.

[7] Ghoddusi, P., Ahmadi, R., \& Sharifi, M. (2010). Fiber pullout model for aligned hooked-end steel fibre. Canadian Journal of Civil Engineering, 37, 1179-1188

[8] Aslani, F., \& Nejadi, S. (2012). Bond characteristics of steel fiber and deformed reinforcing steel bar embedded in steel fiber reinforced selfcompacting concrete (SFRSCC). Central European Journal of Engineering, 445-470.

[9] Abu-Lebdeha, T., Hamousha, S., Heard, W., \& Zornig, B. (2011) Effect of matrix strength on pullout behavior of steel fiber reinforced very-high strength concrete composites. Construction and Building Materials, 25(1), 39-46.

[10] Yaşar, E., Erdogan, Y., \& Kilic, A. (2004). Effect of limestone aggregate type and water-cement ratio on concrete strength. Materials Letters 58(5): 772-777.

[11] McIntosh, J. D. (1966). Concrete mix design. London, cement and concrete association.

[12] Köksala, F., Şahinb, Y. G., \& Yiğitd, İ. (2013). Fracture energy-based optimisation of steel fibre reinforced concretes. Engineering Fracture Mechanics, 107, 29-37.

[13] Greenwood, N. N. \& A. Earnshaw (1984). Chemistry of the elements, Pergamon Press.

[14] Siddique, R. (2011). Utilization of silica fume in concrete: Review of hardened properties. Resources, Conservation and Recycling 55(11): 923-932.

[15] Nili, M., \& Afroughsabet, V. (2010). Combined effect of silica fume and steel fibers on the impact resistance and mechanical properties of concrete. International Journal of Impact Engineering, 37(8), 879886.

[16] Wong, H. S., \& Razak, A. (2005). Efficiency of calcined kaolin and silica fume as cement replacement material for strength performance. Cement and Concrete Composites 35(4): 696-702.

[17] Mazloom, M., Ramezanianpour, A. A., \& Brooks, J. J. (2004). Effect of silica fume on mechanical properties of high-strength concrete. Cement and Concrete Composites, 26(4), 347-357.

[18] Nili, M., \& Afroughsabet, V. (2010). Combined effect of silica fume and steel fibers on the impact resistance and mechanical properties of concrete. International Journal of Impact Engineering, 37(8), 879886.

[19] Chan, Y. W., \& Chu, S. H. (2004). Effect of silica fume on steel fiber bond characteristics in reactive powder concrete. Cement and Concrete Research, 34(7), 1167-1172.

[20] Cook, D. J. (1986). Natural Pozzolanas. Cement Replacement Materials. R. N. Swamy. London, Surrey University press. 3: 1-40.

[21] UK Quality Ash Association. (2004, March 6). ...the power behind PFA. Retrieved from ukqaa: http://www.ukqaa.org.uk/wpcontent/uploads/2014/03/6-sided-re-branded-Mar-2014.pdf

[22] ASTM International. (2003). C618: Standard Specification for Coal Fly Ash and Raw or Calcined Natural Pozzolan for Use in Concrete. Retrieved from http://www.astm.org/

[23] British standard institute. (2012). BS EN 450-1: Fly ash for concrete: Part 1: Definition, specifications and conformity criteria [Electronic version]. London: Author.
[24] Durán-Herrera, A., Juárez, C. A., Valdez, P., \& Bentz, D. P.. (2011). Evaluation of sustainable high-volume fly ash concretes. Cement and Concrete Composites 33(1): 39-45.

[25] Tikkanen, J., Cwirzen, A., \& Penttala, V. (2014). Effects of mineral powders on hydration process and hydration products in normal strength concrete. Construction and Building Materials 72(0), 7-14.

[26] Bederina, M., Makhloufi, Z., \& Bouziani, T. (2011). Effect of Limestone Fillers the Physic-Mechanical Properties of Limestone Concrete. Physics Procedia 21(0), 28-34.

[27] Gesoğlu, M., Güneyisi, E., Kocabağ, M., Bayram, V., \& Mermerdas, K. (2012). Fresh and hardened characteristics of self compacting concretes made with combined use of marble powder, limestone filler, and fly ash. Construction and Building Materials, 37, 160-170.

[28] Bonavetti, V, Donza, H., Menéndez, G., Cabrera, O., \& Irassar, E.F. (2003). Limestone filler cement in low w/c concrete: A rational use of energy. Cement and Concrete Research 33(6): 865-871.

[29] Haktanir, T., Ari, K., Altun, F., Atis, C., \& Karahan, O. (2006). Effects of steel fibers and mineral filler on the water-tightness of concrete pipes. Cement and Concrete Composites, 28(9), 811-816.

[30] Topçu, İ. B. (2013). High-volume ground granulated blast furnace slag (GGBFS) concrete. In F. Pacheco-Torgal, S. Jalali, J. Labrincha and V. M. John (Eds.), Eco-Efficient Concrete (pp. 218240).,Woodhead Publishing..

[31] Concrete Society Working Group. (2011). Technical Report No. 74, Cementitious Materials. Surrey: The Concrete Society.

[32] Bilim, C., Atiş, C. D., Tanyildizi, H., \& Karahan O. (2009). Predicting the compressive strength of ground granulated blast furnace slag concrete using artificial neural network. Advances in Engineering Software 40(5): 334-340.

[33] Bernal, S., De Gutierrez, R., Delvasto, S., \& Rodriguez, E. (2010). Performance of an alkali-activated slag concrete reinforced with steel fibers. Construction and Building Materials 24(2), 208-214.

[34] Dramix 5D 4D 3D data sheets. (2012) Retrieved from http://www.bekaert.com/en/extranet/Construction/productlibrary/dramix-datasheets

[35] British standard institute. (2011). BS EN 197-1: Cement, Composition, specifications and conformity criteria for common cements [Electronic version]. London: Author.

[36] Holland, T. C. (2005). Silica fume user's manual. Lovettsville: Silica Fume Association.

[37] British standard institute. (2009c). BS EN 12390-7: Testing hardened concrete: Part 7: Density of hardened concrete [Electronic version]. London: Author.

[38] British standard institute. (2009b). BS EN 12390-3: Testing hardened concrete: Part 3: Compressive strength of test specimens [Electronic version]. London: Author.

[39] Zile, E., \& Zile, O. (2013). Effect of the fiber geometry on the pullout response of mechanically deformed steel fibers. Cement and Concrete Research 44(0): 18-24.

About Author (s):

Elyas Malaki Zanjani
PhD Student, MSc, BSc
Stephanie Barnett BSc, PhD, PGCert,
MInstP, CPhys, FIMMM, FHEA
David Begg
PhD M.ASCE

